\title{
Validation of 3D echocardiographic volume detection of left atrium by human cadaveric casts
}

\author{
Jouni K. Kuusisto ${ }^{1 *} \mathbb{D}$, Vesa M. Järvinen ${ }^{2}$ and Juha P. Sinisalo ${ }^{1}$
}

\begin{abstract}
Background: Left atrial volume is a prognostic factor in cardiac pathologies. We aimed to validate left atrial volume detection with 3D and 2D echocardiography (3DE and 2DE) by human cadaveric casts. 3DE facilitates measurement of atrial volume without geometrical assumptions or dependence on imaging angle in contrast to 2DE methods.

Methods: For method validation, six water-filled balloons were submerged in a 20-I water tank and their volumes were measured with 3DE. Seven human cadaveric left atrial casts were prepared of silicone and were transformed into ultrasound-permeable casts. Casts were imaged in the same setting, so that 3DE and 2DE of casts represented transthoracic apical view. Left ventricle analysis softwares GE 4D Auto LVQ and TomTec 4D LV-Function were used for 3DE volumetry.

Results: Balloon volumes ranged 37 to $255 \mathrm{ml}$ (mean $126 \mathrm{ml}$ ). 3DE resulted in an excellent volumetric agreement with balloon volumes, absolute bias was $-3.7 \mathrm{ml}(95 \% \mathrm{Cl}-5.9$ to -1.4$)$. Atrial cast volumes were 38 to $94 \mathrm{ml}$ (mean $56.6 \mathrm{ml}$ ). 3DE and 2DE volumes were excellently correlated with cast volumes ( $r=0.96$ to 0.99 ). Biases were for $\mathrm{GE}$ 4D LVQ $-0.7 \mathrm{ml}(95 \% \mathrm{Cl}-6.1$ to 4.6), TomTec 4D LV-Function $3.3 \mathrm{ml}(-1.9$ to 8.5) and 2DE $2.9 \mathrm{ml}$ (- 4.0 to 9.9). 3DE resulted in lower limits of agreement and showed no volume-related bias in contrast to area-length method.

Conclusions: We conclude that measurement of human cadaveric left atrial cast volumes by 3DE is in excellent agreement with true cast volumes.
\end{abstract}

Keywords: Cardiac imaging, Echocardiography, LAV, 3DE, 2DE, Area-length method, In vitro

\section{Background}

Left atrial (LA) volume and depressed function of LA are prognostic factors of adverse cardiovascular events in cardiac pathologies, such as atrial fibrillation, heart failure and coronary artery disease [1-5], and in general population [6]. LA size can be estimated by measuring its diameter, which is associated with cardiac events, but has limited correlation to atrial volume [7]. Calculated LA volumes by two-dimensional echocardiographic (2DE) methods are stronger predictors of adverse outcomes in comparison with LA diameter or LA cross sectional area [8]. 2DE methods are recommended for the volumetric assessment in the current guideline of

\footnotetext{
* Correspondence: jouni.kuusisto@iki.fi

${ }^{1}$ Division of Cardiology, Heart and Lung Center, Helsinki University Central Hospital, Meilahti Tower Hospital, P.O. Box 340, FIN-00029 HUS Helsinki, Finland

Full list of author information is available at the end of the article
}

echocardiographic chamber quantification [9] and in recommendation of cardiac imaging in atrial fibrillation [10]. Still an underestimation of volume by $2 \mathrm{DE}$ methods is evident $[11,12]$. Three-dimensional echocardiography (3DE) provides measure of LA volume without geometrical assumptions, which are implied in $2 \mathrm{DE}$ methods. Agreement of $3 \mathrm{DE}$ is shown to be good in comparison to cardiac magnetic resonance imaging, although there is some discrepancy in results, which might be due to various factors i.e. different imaging hardware, imaging settings and analysis algorithms. [13-15] Cardiac magnetic resonance is considered gold standard in left atrial volumetry.

Previously Chen et al. validated in vitro 3DE volume detection by excised porcine hearts for right ventricle and demonstrated superiority of 3DE over $2 \mathrm{DE}$ methods [16]. In 2001 Teupe et al. used 3DE to measure normal

(c) The Author(s). 2018 Open Access This article is distributed under the terms of the Creative Commons Attribution 4.0 International License (http://creativecommons.org/licenses/by/4.0/), which permits unrestricted use, distribution, and 
and aneurysmal left ventricles of excised pig hearts to demonstrate accuracy of 3DE volumetric method [17]. In vitro validation of cardiac MRI volume detection has been demonstrated for both human atria by human cadaveric casts $[18,19]$.

In this study, we imaged human cadaveric left atrial casts by $3 \mathrm{DE}$ and $2 \mathrm{DE}$ to test agreement of volumetric methods to true cast volumes measured by water displacement. We also imaged water-filled balloons to test $3 \mathrm{DE}$ in wider range of volumes and to validate most appropriate placement of volumetric borderline in measurements.

\section{Methods}

\section{Materials}

Six latex balloons were filled with water to represent volumes of LA both in normal physiological conditions and in left atrial enlargement. The balloons were relatively spherical in shape and their walls provided easily distinguishable ultrasound echo for analysis.

Seven human cadaveric LA casts were prepared in the Department of Forensic Medicine, Helsinki University, Finland. No fixation of cardiac tissues was used. Mitral valves and ventricular apices were removed, and the pulmonary veins were clamped. Hearts were suspended from apical portion and left hearts were filled with silicone rubber without extra filling pressure. After hardening of the silicone rubber, the casts were removed from the hearts. LA parts of the casts were separated from ventricular parts at the mitral annular level. These casts were previously used in magnetic resonance imaging studies by Järvinen and Jauhiainen in the 1990s [18, 19]. At that time, no approval of ethics committee was required and the study was approved by head of department.

For this study the silicone casts were transformed to casts made of agar-agar, as casts of silicone rubber are not permeable to ultrasound. Molds for agar-agar casts were made from latex rubber, which was applied on the primary silicone casts while they were stabilized at their mitral planes to a level surface. Four layers of latex rubber was applied on each silicone cast. Left atrial appendices were excluded at this point from the latex molds, as they are usually not included in the volumetric assessment of left atrium by transthoracic ultrasound. The latex molds were peeled from silicone casts and two further layers of latex rubber were used to shut the open left atrial appendix orifices. The latex molds were then positioned so that the mitral openings were facing upwards. A 1,5\% agar-agar and water solution was prepared by heating until boiling and then poured into the latex molds at the temperature of 60 degrees centigrade. The molds were cast until the level of mitral annulus.
The agar-agar casts were refrigerated overnight and then they were carefully removed from the molds (Fig. 1a).

\section{Determination of cast and balloon volumes}

True volumes of the balloons were determined by weighing the water-filled balloons, assuming one gram of weight representing one milliliter of volume. The weight of the balloons before filling with water were measured to be insignificantly low.

True volumes of the agar-agar casts were determined by volume displacement method. A vessel with an opening on its side was filled with water up to the lower level of the opening. The casts were carefully submerged in to the water and the displaced water was collected through the opening into a $100-\mathrm{ml}$ measuring glass. The volume of the displaced water was assumed to be the true volume of the cast. Volumes were determined by this method before and right after imaging to detect whether the cast volumes had been affected by the immersion into water during imaging.

\section{Imaging}

GE Vivid E9 machine with $4 \mathrm{~V}$ probe (GE Vingmed Ultrasound AS, Horten, Norway) was used for both 3DE and 2DE imaging. The agar-agar casts were immersed in a twenty-liter tank for imaging. Water mixture with dried and crushed seeds of Plantago ovata was used as the imaging medium, as enhanced contrast of the water was necessary for the semi-automated volumetry softwares to function properly. Higher signal intensity of the medium than that of casts represents the relative signal intensities in the in vivo measurements where signal intensity from myocardium and other surrounding tissues is higher than from blood in the atrial cavity. Coarse cloth was placed on the bottom of the tank to attenuate reverberation. The probe was supported above the tank by a tripod so that lens of the probe was $10 \mathrm{~mm}$ below the water surface and orienting downwards.

The casts were stationed on a thin (diameter $3 \mathrm{~mm}$ ) wooden support attached to a pedestal on the bottom of the tank to stabilize the cast during imaging, and the casts were positioned to represent transthoracic apical view. Mitral annular level of the cast was horizontal and thus perpendicular to ultrasound wave propagation. The orifice of left atrial appendix was positioned 60 degrees counterclockwise from the $2 \mathrm{DE}$ view so that the first aspect of the imaging represented the apical four chamber view. The ultrasound beam was then electronically rotated 60 degrees counterclockwise to obtain two chamber view. Zoomed $4 \mathrm{D}$ view was used to collect $3 \mathrm{DE}$ volumetric data over 4 to 6 cardiac cycles, which were defined from electrocardiogram recorded from researcher at a heat rate of 65 to $70 \mathrm{bpm}$. The gain was optimized by eye for best possible delineation. Recorded 

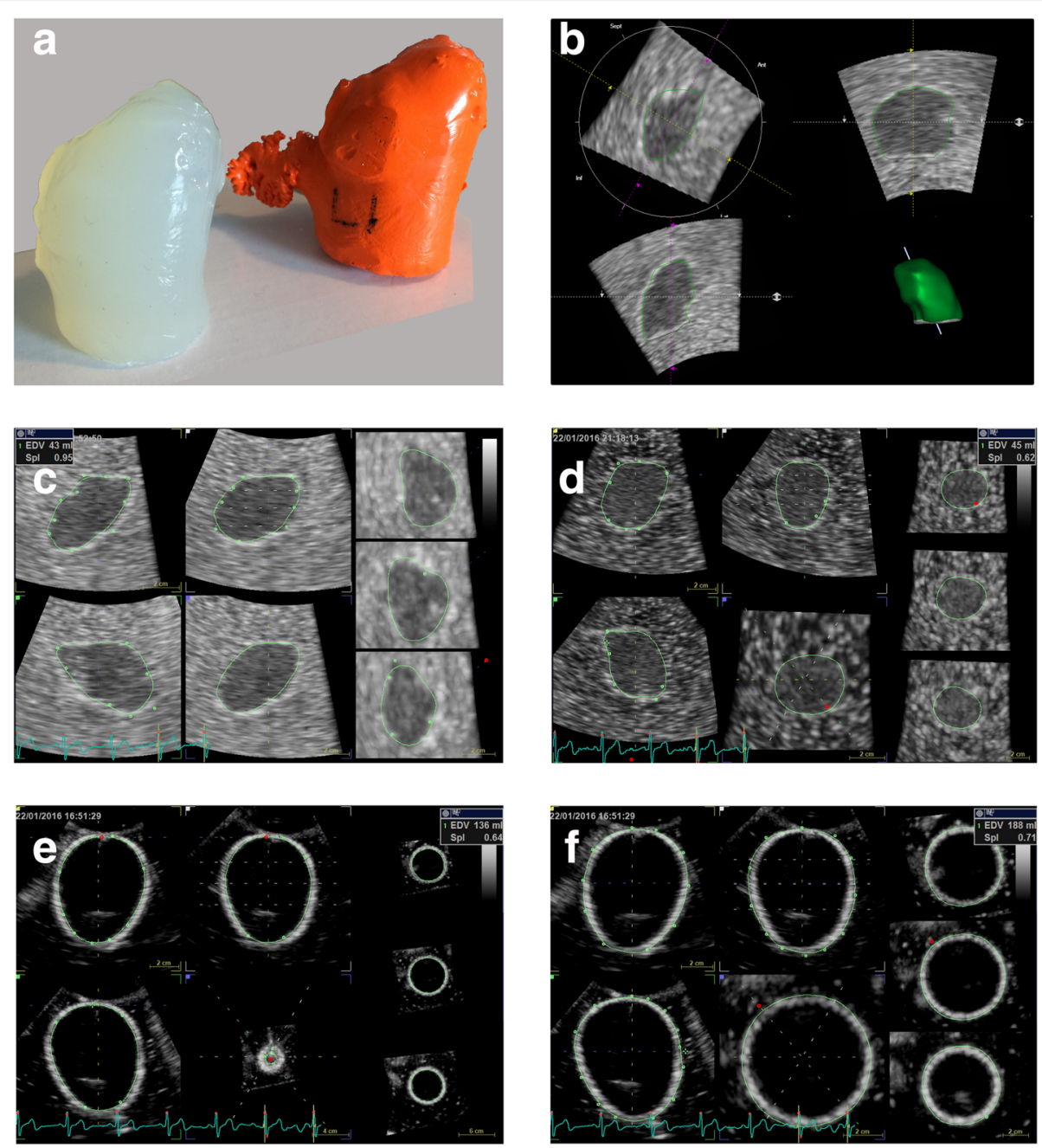

Fig. 1 a) Human cadaveric left atrial silicone cast (on right) and its transformed agar-agar cast without left atrial appendage, b) 3D echocardiographic volume analysis of cast no. 4 by TomTec 4D LV-Function (true volume $43 \mathrm{ml}$, measured volume $42 \mathrm{ml}$ ) and by c) GE 4D LVQ (measured volume $43 \mathrm{ml}$ ), d) cast no. 5 by GE 4d LVQ (true volume $44 \mathrm{ml}$, measured volume $45 \mathrm{ml}$ ), e) 3D volume measurement by GE 4D LVQ of a balloon with borderline on the inner aspect (true volume $140 \mathrm{ml}$, measured volume $136 \mathrm{ml}$ ) and $\mathbf{f}$ ) on the outer aspect (measured volume $188 \mathrm{ml}$ )

volume size and probe frequency were adjusted so that the volume frame rate was 35 to $50 \mathrm{~Hz}$ which is the typical acquisition frequency when imaging dynamic volume in vivo.

Water balloons were stationed by a thread and weight to the bottom of the tank so that the center of the balloons was approximately at $100 \mathrm{~mm}$ distance from the lens of the probe. 3DE images were collected similarly. No contrast enhancement agent was used during balloon imaging.

\section{Image analysis}

Image analysis was performed offline with GE EchoPAC work station software version 112.1.1 (GE Vingmed Ultrasound AS, Horten, Norway) after imaging. GE EchoPAC 4D LVQ (Figs. 1c-f) and TomTec 4D
LV-Function (TomTec Imaging Systems GmbH, Unterschleissheim, Germany) (Fig. 1b) softwares were used for volume analysis. Both softwares are designed for cardiac left ventricle volume analysis, but they can also be applied for LA volumetry, as we demonstrate in this study. The researcher was blinded to the weights of the balloons and the results of volume displacement representing true volumes of balloons and casts.

There was a distinct border echo in the ultrasound images at the interface of water as medium, balloon wall, and water inside the balloon. This border echo thickness in the images was clearly greater than that of the balloon true walls $(<1 \mathrm{~mm})$. To assess the most appropriate approach of volumetric measurement, the borderline was placed on the inner (Fig. 1e) and outer rims (Fig. 1f), and to the middle of this border echo by GE $4 \mathrm{D}$ LVQ. 
Automation of TomTec software assumed the borderline to the inner aspect of the rim, so only this approach was used by TomTec software.

Measurements from the ultrasound images representing apical view during cast imaging were 1) 3DE volumetry by both softwares, 2) LA cast cross section areas from four and two chamber views and 3) the greatest length of these cross sections from middle of mitral orifice area to the roof of the atrial casts. The four and two chamber areas and their respective lengths were used to calculate approximations of volumes by biplane area-length method (A-L method) by equation $\frac{8}{3 \pi}$ $\times \frac{4 \text { ch_area } \times 2 \text { ch_area }}{\text { length }}$, where length is the shorter of the two measured lengths. Repeatability was tested for 3DE volumetry and A-L method of left atrial casts by a time interval of two weeks between repeated measurements.

\section{Statistical and data analyses}

IBM SPSS for Macintosh version 24.0 (Armonk, NY, USA) and Microsoft Excel for Mac version 15.26 (Microsoft Corporation, Redmond, WA, USA) were used for statistical and data analyses. Mean and range of true and measured volumes of balloons were determined. Paired differences of measured volumes to true volumes were calculated. Mean of these differences were considered bias. 95\% confidence intervals $(95 \% \mathrm{CI})$ for bias and limits of agreement (LOA), defined as bias \pm 1.96 standard deviations, were calculated. LOA represent the range in which $95 \%$ of measured volumes differ from true volumes when normal distribution is assumed. Pearson correlation coefficients and their statistical significances were calculated. The same statistical methods were applied for repeated volumetric measurements in addition to intraclass correlation coefficients and their statistical significance. Two-way mixed testing for absolute agreement was used for intraclass correlation. Bland-Altman difference plots were used to visualize data.

\section{Results}

\section{Balloon imaging}

True volumes of the water balloons ranged from 37 to $255 \mathrm{ml}$ and mean volume was $126 \mathrm{ml}$. All the tested 3DE volumetric methods, including all borderline placements by GE $4 \mathrm{D} \mathrm{LVQ}$, to measure balloon volumes resulted in very high correlations to true volumes (Pearson $r>0.999, p<0.0005)$. Balloon wall echo thickness was 1 to $6 \mathrm{~mm}$ and it was lowest in areas where ultrasound wave propagation was perpendicular to the wall balloon wall. Placement of the borderline on the inner aspect of the balloon wall echo by GE 4D LVQ resulted lowest absolute bias $-3.7 \mathrm{ml}(95 \% \mathrm{CI}-5.9$ to -1.4$)$ and the bias did not correlate to volume (Pearson $r=-0.36, p=$ 0.481 ). LOA were -7.9 to $0.6 \mathrm{ml}$. Placement of borderline to the midline or outer aspect of the wall echo produced volume dependent overestimation of the volume and the biases were $15.5 \mathrm{ml}$ (95\% CI 4.7 to 26.3 ) and $44.2 \mathrm{ml}$ (11.4 to 77.0), respectively. With TomTec software the bias was inversely related to volume resulting in greater negative bias in larger observed volumes. Mean bias was $-24,3 \mathrm{ml}(95 \% \mathrm{CI}-37.8$ to -10.8$)$ with TomTec. As noted previously, semi-automation in TomTec software prevented precise manual adjustments to the borderline.

\section{Cast imaging}

Agar-agar cast volumes determined by volume displacement ranged from 38 to $94 \mathrm{ml}$ (mean $56.6 \mathrm{ml}$ ). Repeated volume displacement measurements before and after imaging resulted in maximum of $2 \mathrm{ml}$ difference. The measured volume displacement before the imaging was used in the later analyses.

The interface with the medium and agar-agar left atrial casts produced less prominent wall echo than with balloon imaging. As suggested most appropriate by balloon measurements, the borderline was placed closely to inner aspect of the echo representing interface of the cast and medium during 3DE volumetry and A-L method. Pearson correlation coefficients of measured volumes to true volumes for all methods were high and 95\% CI of biases for these methods included zero bias. 3DE volumetric measurements with both softwares resulted in narrower limits of agreement in comparison to A-L method. With A-L method bias was positively correlated with volume (Pearson $\mathrm{r}$ of difference to true volume was $0.837(p<0.05))$, but no statistically significant volume dependent bias was observed in 3DE methods (GE 4d LVQ $p=0.96$ and TomTec 4d LV-Function $p=$ $0.24)$. Measured volumes for casts, their displaced volumes and statistic characteristics are presented in Table 1 and Fig. 2a. Bland-Altman difference plots visualize the observed differences, biases and limits of agreement (Figs. 2b-d).

\section{Repeatability}

Repeated 3DE and A-L method volumetric measurements were performed to test repeatability. Both Pearson and intraclass correlation coefficients indicated very good repeatability $(r=0.975$ to 0.982 , intraclass correlation coefficients 0.967 to 0.980 ). Results of these measurements are depicted in Table 2. Bland-Altman charts describe the relation of measurement differences to average volumes of measurements (Figs. 3a-c).

\section{Discussion}

In this study we tested the applicability of $3 \mathrm{D}$ and $2 \mathrm{D}$ echocardiographic volumetric methods in determining volumes of human left atrial casts. To our knowledge 
Table $13 D E$ volumetric measurements and 2DE calculated volumes of left atrial human cadaveric casts in comparison to their true volumes

\begin{tabular}{|c|c|c|c|c|c|c|c|}
\hline \multirow[b]{2}{*}{ cast no. } & \multirow[b]{2}{*}{ true volume (ml) } & \multicolumn{2}{|c|}{ 3DE volume: GE 4D LVQ } & \multicolumn{2}{|c|}{ 3DE volume: TomTec LV } & \multicolumn{2}{|l|}{ 2DE volume } \\
\hline & & $\begin{array}{l}\text { measured } \\
\text { volume (ml) }\end{array}$ & $\begin{array}{l}\text { difference to } \\
\text { true volume (ml) }\end{array}$ & $\begin{array}{l}\text { measured } \\
\text { volume }(\mathrm{ml})\end{array}$ & $\begin{array}{l}\text { difference to } \\
\text { true volume (ml) }\end{array}$ & $\begin{array}{l}\text { calculated } \\
\text { volume (ml) }\end{array}$ & $\begin{array}{l}\text { difference to } \\
\text { true volume (ml) }\end{array}$ \\
\hline 1 & 38 & 36 & -2 & 36 & -2 & 35 & -3 \\
\hline 2 & 94 & 94 & 0 & 103 & 9 & 106 & 12 \\
\hline 3 & 51 & 43 & -8 & 50 & -1 & 55 & 4 \\
\hline 4 & 43 & 43 & 0 & 42 & -1 & 36 & -7 \\
\hline 5 & 44 & 45 & 1 & 50 & 6 & 40 & -4 \\
\hline 6 & 58 & 68 & 10 & 70 & 12 & 68 & 10 \\
\hline 7 & 68 & 62 & -6 & 68 & 0 & 76 & 8 \\
\hline mean $(95 \% \mathrm{Cl})$ & 56.6 & 55.9 & $-0.7(-6.1-4.6)$ & 59.9 & $3.3(-1.9-8.5)$ & 59.5 & $2.9(-4.0-9.9)$ \\
\hline SD & 19.4 & 20.3 & 5.8 & 22.8 & 5.6 & 26.0 & 7.5 \\
\hline range & $38-94$ & $36-94$ & $-8-10$ & $36-103$ & $-2-12$ & $35-106$ & $-7-12$ \\
\hline LOA & & & $-12.1-10.6$ & & $-7.8-14.4$ & & $-11.9-17.6$ \\
\hline r & & \multicolumn{2}{|c|}{$0.959(p=0.001)$} & \multicolumn{2}{|c|}{$0.977(p=0.0002)$} & \multicolumn{2}{|c|}{$0.988(p=0.00003)$} \\
\hline
\end{tabular}

95\% Cl - 95\% confidence interval, 2DE volume - volume calculated by 2D echocardiographic biplane area-length method, 3DE volume: GE 4D LVQ and 3DE volume: TomTec LV - 3D echocardiographic volume measured by GE 4D LVQ and TomTec 4D LV-Function softwares, respectively, LOA - limits of agreement defined as mean \pm 1.96 SD, $r$ - Pearson correlation coefficient, SD - standard deviation

2

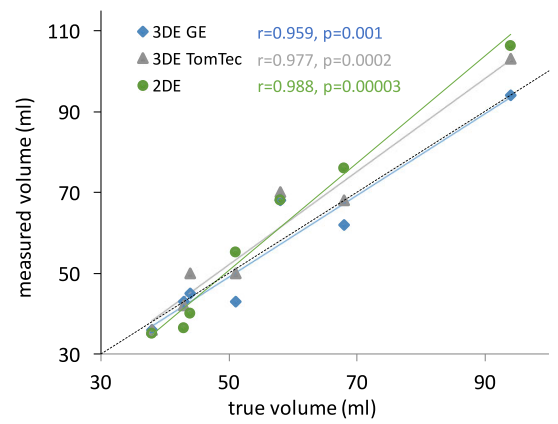

C

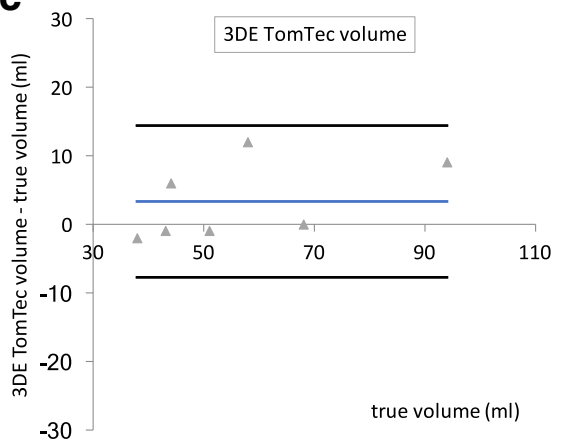

b

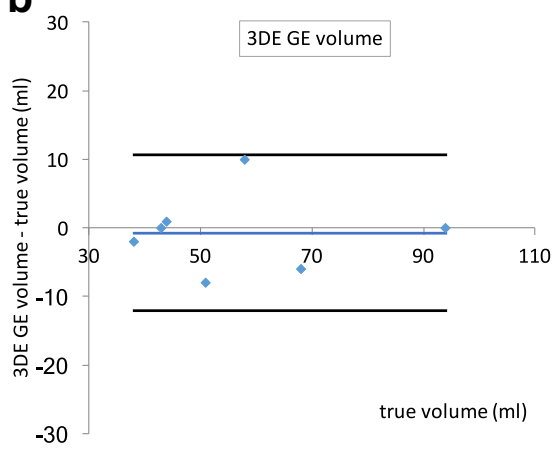

d

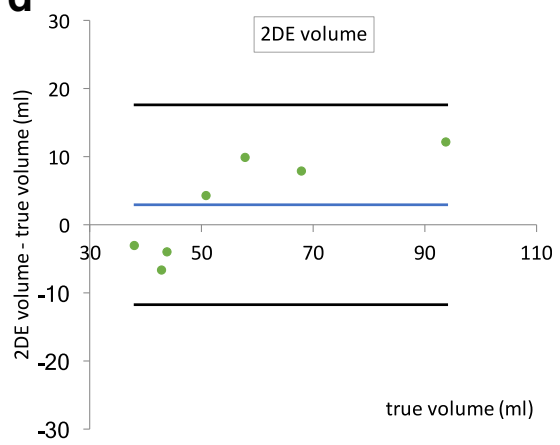

Fig. 2 Results of human left atrial cast volume measurements by 3DE and 2DE. a) 3DE and 2DE volumes in comparison to true volumes of casts. b-d) Bland-Altman paired difference plots of volumetric measurements in comparison to true volumes. Black lines represent limits of agreement (mean $\pm 1.96 \mathrm{SD}$ ) and blue lines bias. 2DE volume - volume calculated by 2D echocardiographic biplane area-length method, 3DE GE and 3DE TomTec - 3D echocardiographic volume measured by GE 4D LVQ and TomTec 4D LV-Function softwares, respectively, $r$ - Pearson correlation coefficient. 
Table 2 Repeated 3D volumetric measurements and 2D calculated volumes of left atrial human cadaveric casts

\begin{tabular}{|c|c|c|c|c|c|c|c|c|c|}
\hline \multirow[t]{2}{*}{ cast no. } & \multicolumn{3}{|c|}{ 3DE volume: GE 4D LVQ } & \multicolumn{3}{|c|}{ 3DE volume: TomTec LV } & \multicolumn{3}{|l|}{ 2DE volume } \\
\hline & meas. $1(\mathrm{ml})$ & meas. $2(\mathrm{ml})$ & difference (ml) & meas. $1(\mathrm{ml})$ & meas. $2(\mathrm{ml})$ & difference (ml) & meas. $1(\mathrm{ml})$ & meas. 2 (ml) & difference (ml) \\
\hline 1 & 36 & 35 & -1 & 36 & 40 & 4 & 35 & 35 & 0 \\
\hline 2 & 94 & 88 & -6 & 103 & 102 & -1 & 106 & 103 & -3 \\
\hline 3 & 43 & 44 & 1 & 50 & 59 & 9 & 55 & 66 & 11 \\
\hline 4 & 43 & 41 & -2 & 42 & 40 & -2 & 36 & 33 & -3 \\
\hline 5 & 45 & 47 & 2 & 50 & 46 & -4 & 40 & 48 & 8 \\
\hline 6 & 68 & 57 & -11 & 70 & 67 & -3 & 68 & 68 & 0 \\
\hline 7 & 62 & 60 & -2 & 68 & 72 & 4 & 76 & 84 & 8 \\
\hline mean $(95 \% \mathrm{Cl})$ & 55.9 & 53.1 & $-2.7(-6.8-1.4)$ & 59.9 & 60.9 & $1.0(-3.4-5.4)$ & 59.4 & 62.4 & $3.0(-2.4-8.4)$ \\
\hline SD & 20.3 & 17.7 & 4.5 & 22.8 & 22.2 & 4.8 & 26.0 & 25.8 & 5.8 \\
\hline range & $36-94$ & $35-88$ & $-11-2$ & $36-103$ & 40-102 & $-4-9$ & $35-106$ & $33-103$ & $-3-11$ \\
\hline LOA & & & $-11.5-6.0$ & & & $-8.3-10.3$ & & & $-8.4-14.4$ \\
\hline r & \multicolumn{3}{|c|}{$0.982, p=0.0001$} & \multicolumn{3}{|c|}{$0.978, p=0.0001$} & \multicolumn{3}{|c|}{$0.975, p=0.0002$} \\
\hline ICC (95\% Cl) & \multicolumn{3}{|c|}{$0.967(0.819-0.994), p=0.00003$} & \multicolumn{3}{|c|}{$0.980(0.894-0.996), p=0.00001$} & \multicolumn{3}{|c|}{$0.972(0.857-0.995), p=0.00002$} \\
\hline
\end{tabular}

95\% Cl - 95\% confidence interval, 2DE volume - volume calculated by 2D echocardiographic biplane area-length method, 3DE volume: GE 4D LVQ and 3DE volume: TomTec LV - 3D echocardiographic volume measured by GE 4D LVQ and TomTec 4D LV-Function softwares, respectively, ICC - intraclass correlation coefficient, LOA - limits of agreement defined as mean \pm 1.96 SD, meas. 1 and meas. $2 \neg$ first and repeated measurement, $r$ - Pearson correlation coefficient for meas. 1 and meas. 2, SD - standard deviation
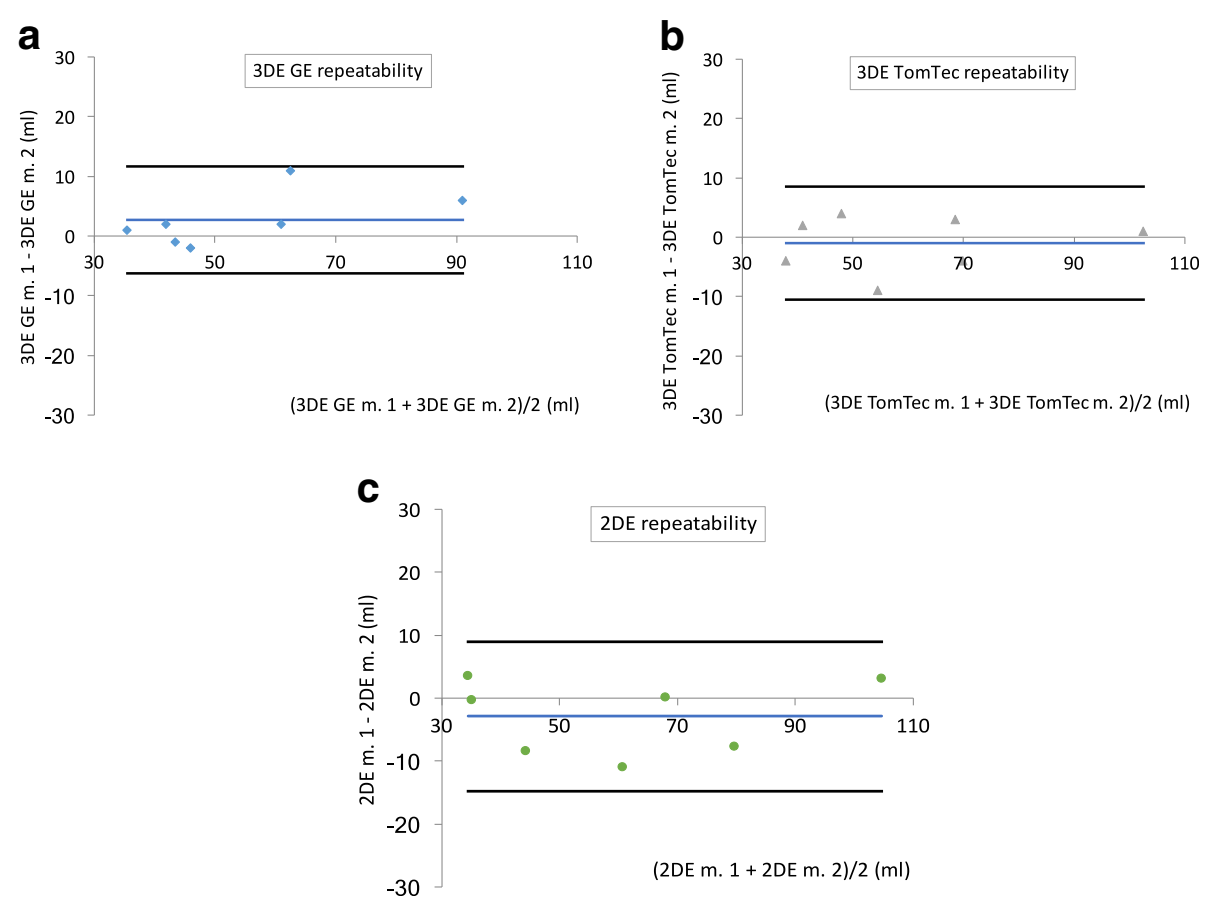

Fig. 3 Results of repeated measurements of human left atrial cast volumes. Bland-Altman paired difference plots of repeated volumetric measurements of casts in comparison to mean of measured volumes. Black lines represent limits of agreement (mean $\pm 1.96 \mathrm{SD}$ ) and blue lines mean of differences to paired averages of measured volumes. a 3DE GE repeatability - 3D echocardiographic repeated volume measurements by GE 4D LVQ software, b 3DE TomTec repeatability - 3D echocardiographic repeated volume measurements by TomTec 4D LV-Function software, c 2DE repeatability - repeated calculated volumes by biplane area-length method, $\mathrm{m} .1$ and $\mathrm{m}$. 2 - first and repeated measurement 
validation of left atrial volumetry in this setting has not been done previously. We showed that 3DE volumetry of water-filled balloons is in excellent absolute agreement with true volumes of the balloons when volumetric borderlines were placed closely on the inner aspect of the balloon wall echo. We found 3DE methods to be equally or more accurate in comparison to 2DE represented by biplane area-length method, considering lower observed limits of agreement and lack of volume dependent bias with 3DE. All methods had excellent correlation to true cast volumes and were well repeatable.

With 2DE volumetric methods there are inherent assumptions of geometrical symmetricity. With biplane area-length method an ellipsoid, and with monoplane area-length a spheroid shape is assumed. In addition to this geometrical assumption, the in vivo transthoracic apical views that are oriented along the left ventricular axis might not represent the left atrial axis. The planimetered area and length of the left atrium can thus be a misestimation resulting in an unpredictable error in estimation of the atrial volume [20]. Underestimation of volume by A-L method in comparison to cardiac magnetic resonance imaging is reported [21, 22]. With $3 \mathrm{DE}$ volumetry there is no need for geometrical assumptions or for orienting the echocardiographic beam along the left ventricular or atrial axis as the volume is measured along the true borders of the chamber.

Casting process and post mortem state might have affected volumes and shapes of the casts, and possible prior medical conditions of the deceased are not known. For the scope of this study we did not consider this a limitation as we aimed for volumetric validation of casts that represent the variable sizes and shapes of human left atria. Regarding some casts, areas of the interface of the cast and the medium were not explicit which at least partly contributed both to error in volumetric measurements to true volumes and repeatability. Different choice of medium or cast material could have mitigated this issue. In vitro repeatability in this study is likely better in comparison to clinical setting which has more variability in the imaging conditions.

The walls of water-filled balloons produced distinct echo lining in the images which we speculate to be at least partly due to interference of the transmitted ultrasound signal and the balloon wall. In cast imaging the interface consists of transition from contrast enhanced water to cast as a medium for ultrasound propagation which probably induces less artifacts in comparison to balloon wall. We noted, however, a less pronounced lining in the images also during cast imaging. The contrast enhanced water tended to turn less homogenous over time and stirring of the medium was required intermittently. We speculate this lining during cast imaging to consist mostly of the contrast enhanced medium, not the cast itself, giving a rationale for the placement of the volumetric borderline to inner aspect of the interface.

\section{Conclusions}

We conclude that $3 \mathrm{DE}$ is an accurate and feasible method to image left atrial volume in this in vitro study. Commercially available software (GE 4D LVQ and TomTec 4D LV-Function) developed for the left ventricular volume analysis can be used in the left atrial volume analysis as well.

\section{Abbreviations}

2DE: Two-dimensional echocardiography; 3DE: Three-dimensional echocardiography; 95\% Cl: 95\% confidence interval; A-L Method: Biplane area-length method; LA: Left atrium; LOA: Limits of agreement

\section{Acknowledgements}

We are thankful for English revision to Pekka Järvinen, MSc.

Funding

Dr. Kuusisto was funded by The Education Fund, Finland.

\section{Availability of data and materials}

The datasets used and/or analysed during the current study are available from the corresponding author on reasonable request.

\section{Authors' contributions}

JK and VJ performed preparation and imaging of the casts. JK analysed the data. JS, VJ and JK interpreted the data and had major contribution in writing the manuscript. All authors read and approved the final manuscript.

\section{Ethics approval}

The primary casts were prepared for studies performed in 1990's. At that time, no ethics committee approval was required. These casts prepared then were for this study further transformed to ultrasound permeable casts and there was no further interaction with humans or animals.

\section{Consent for publication}

Not applicable.

\section{Competing interests}

The authors declare that they have no competing interests.

\section{Publisher's Note}

Springer Nature remains neutral with regard to jurisdictional claims in published maps and institutional affiliations.

\section{Author details}

'Division of Cardiology, Heart and Lung Center, Helsinki University Central Hospital, Meilahti Tower Hospital, P.O. Box 340, FIN-00029 HUS Helsinki, Finland. ${ }^{2}$ Department of Clinical Physiology, Medical Imaging Center, Hospital District Helsinki and Uusimaa, Hyvinkää Hospital, Hyvinkää, Finland.

Received: 13 December 2017 Accepted: 22 October 2018

Published online: 15 November 2018

\section{References}

1. Gupta DK, Shah AM, Giugliano RP, Ruff CT, Antman EM, Grip LT, et al. Left atrial structure and function in atrial fibrillation: ENGAGE AF-TIMI 48. Eur Heart J. 2014. https://doi.org/10.1093/eurheartj/eht500.

2. Santos ABS, Kraigher-Krainer E, Gupta DK, Claggett B, Zile MR, Pieske B, et al. Impaired left atrial function in heart failure with preserved ejection fraction. Eur J Heart Fail. 2014. https://doi.org/10.1002/ejhf.147.

3. Pellicori P, Zhang J, Lukaschuk E, Joseph AC, Bourantas CV, Loh H, et al. Left atrial function measured by cardiac magnetic resonance imaging in patients with heart failure: clinical associations and prognostic value. Eur Heart J. 2015. https://doi.org/10.1093/eurheartj/ehu405. 
4. Ristow B, Ali S, Whooley MA, Schiller NB. Usefulness of left atrial volume index to predict heart failure hospitalization and mortality in ambulatory patients with coronary heart disease and comparison to left ventricular ejection fraction (from the heart and soul study). Am J Cardiol. 2008. https://doi.org/10.1016/j.amjcard.2008.02.099.

5. Gulati A, Ismail TF, Jabbour A, Ismail NA, Morarji K, Ali A, et al. Clinical utility and prognostic value of left atrial volume assessment by cardiovascular magnetic resonance in non-ischaemic dilated cardiomyopathy. Eur J Heart Fail. 2013. https://doi.org/10.1093/eurjhf/hft019.

6. Tsang TSM, Barnes ME, Gersh BJ, Takemoto Y, Rosales AG, Bailey KR, et al. Prediction of risk for first age-related cardiovascular events in an elderly population: the incremental value of echocardiography. J Am Coll Cardiol. 2003. https://doi.org/10.1016/S0735-1097(03)00943-4.

7. Lester SJ, Ryan EW, Schiller NB, Foster E. Best method in clinical practice and in research studies to determine left atrial size. Am J Cardiol. 1999. https://doi.org/10.1016/S0002-9149(99)00446-4

8. Tsang TSM, Abhayaratna WP, Barnes ME, Miyasaka Y, Gersh BJ, Bailey KR, et al. Prediction of cardiovascular outcomes with left atrial size. J Am Coll Cardiol. 2006. https://doi.org/10.1016/j.jacc.2005.08.077.

9. Lang RM, Badano LP, Mor-Avi V, Afilalo J, Armstrong A, Ernande L, et al. Recommendations for cardiac chamber quantification by echocardiography in adults: an update from the American Society of Echocardiography and the European Association of Cardiovascular Imaging. J Am Soc Echocardiogr. 2015. https://doi.org/10.1016/j.echo.2014.10.003.

10. Donal E, Lip GYH, Galderisi M, Goette A, Shah D, Marwan M, et al. EACVI/ EHRA expert consensus document on the role of multi-modality imaging for the evaluation of patients with atrial fibrillation. Eur Heart J Cardiovasc Imaging. 2016. https://doi.org/10.1093/ehjci/jev354.

11. Kühl JT, Lønborg J, Fuchs A, Andersen MJ, Vejlstrup N, Kelbæk H, et al. Assessment of left atrial volume and function: a comparative study between echocardiography, magnetic resonance imaging and multi slice computed tomography. Int J Cardiovasc Imaging. 2012. https://doi.org/10.1007/s10554011-9930-2

12. Avelar E, Durst R, Rosito GA, Thangaroopan M, Kumar S, Tournoux F, et al. Comparison of the accuracy of multidetector computed tomography versus two-dimensional echocardiography to measure left atrial volume. Am J Cardiol. 2010. https://doi.org/10.1016/j.amjcard.2010.02.021.

13. Mor-Avi V, Yodwut C, Jenkins C, Kühl H, Nesser H-J, Marwick TH, et al. Realtime 3D echocardiographic quantification of left atrial volume. Multicenter Study for Validation With CMR JACC Cardiovasc Imaging. 2012. https://doi. org/10.1016/j.jcmg.2012.05.011

14. Artang R, Migrino RQ, Harmann L, Bowers M, Woods TD. Left atrial volume measurement with automated border detection by 3-dimensional echocardiography: comparison with magnetic resonance imaging. Cardiovasc Ultrasound. 2009. https://doi.org/10.1186/1476-7120-7-16.

15. Perez de Isla L, Feltes G, Moreno J, Martinez W, Saltijeral A, de Agustin JA, et al. Quantification of left atrial volumes using three-dimensional wal motion tracking echocardiographic technology: comparison with cardiac magnetic resonance. Eur Hear J - Cardiovasc Imaging. 2014. https://doi.org/ 10.1093/ehjci/jeu001.

16. Chen G, Sun K, Huang G. In vitro validation of right ventricular volume and mass measurement by real-time three-dimensional echocardiography. Echocardiography. 2006. https://doi.org/10.1111/j.1540-8175.2006.00221.x.

17. Teupe C, Takeuchi M, Ram SP, Pandian NG. Three-dimensional echocardiography: in-vitro validation of a new, voxel-based method for rapid quantification of ventricular volume in normal and aneurysmal left ventricles. Int J Card Imaging. 2001. https://doi.org/10.1023/A: 1010671305700

18. Järvinen VM, Kupari MM, Hekali PE, Poutanen V-P. Assessment of left atrial volumes and phasic function using cine magnetic resonance imaging in normal subjects. Am J Cardiol. 1994. https://doi.org/10.1016/00029149(94)90298-4

19. Jauhiainen $T$, Järvinen VM, Hekali PE, Poutanen VP, Penttilä A, Kupari M. MR gradient echo volumetric analysis of human cardiac casts: focus on the right ventricle. J Comput Assist Tomogr. 1998. https://doi.org/10.1097/ 00004728-199811000-00012.

20. Kebed K, Kruse E, Addetia K, Ciszek B, Thykattil M, Guile B, et al. Atrialfocused views improve the accuracy of two-dimensional echocardiographic measurements of the left and right atrial volumes: a contribution to the increase in normal values in the guidelines update. Int J Cardiovasc Imaging. 2016. https://doi.org/10.1007/s10554-016-0988-8.
21. Whitlock M, Garg A, Gelow J, Jacobson T, Broberg C. Comparison of left and right atrial volume by echocardiography versus cardiac magnetic resonance imaging using the area-length method. Am J Cardiol. 2010. https://doi.org/ 10.1016/j.amjcard.2010.06.065.

22. Rabbat MG, Wilber D, Thomas K, Malick O, Bashir A, Agrawal A, et al. Left atrial volume assessment in atrial fibrillation using multimodality imaging: a comparison of echocardiography, invasive three-dimensional CARTO and cardiac magnetic resonance imaging. Int J Cardiovasc Imaging. 2015. https://doi.org/10.1007/s10554-015-0641-y.

\section{Ready to submit your research? Choose BMC and benefit from:}

- fast, convenient online submission

- thorough peer review by experienced researchers in your field

- rapid publication on acceptance

- support for research data, including large and complex data types

- gold Open Access which fosters wider collaboration and increased citations

- maximum visibility for your research: over $100 \mathrm{M}$ website views per year

At $\mathrm{BMC}$, research is always in progress.

Learn more biomedcentral.com/submissions 